\title{
Transcription Factor E2-Alpha
}

National Cancer Institute

\section{Source}

National Cancer Institute. Transcription Factor E2-Alpha. NCI Thesaurus. Code C30079.

Transcription factor E2-alpha (654 aa, 68 kDa) is encoded by the human TCF3 gene.

This protein plays a role in transcriptional regulation, cell cycle progression and cell lineage commitment. 